\title{
QUALITY IMPROVEMENT IN HEALTH CARE - A FUNDAMENTAL ANALYSIS AND SOUTH AFRICAN PERSPECTIVE
}

\author{
ME Muller
}

\begin{abstract}
This article is based on the opening address that was delivered at a national conference with the launching of the South African Society for Quality in Health Care (SASQuaH). The quality improvement process and principles are analyzed, as well as an exposition of the South African situation. The concepts regarding quality. quality improvement and quality assurance are clarified, the different stakeholders in formalised quality improvement explained, as well as the motives for and principles of quality improvement in health services. The different external and intermal mechanisms in quality improvement are analyzed, including the principle of community ownership and international collaboration. Continuous development and capacity building regarding quality improvement is recommended at all levels of health service delivery.
\end{abstract}

\section{OPSOMMING}

Hierdie artikel is gebaseer op die openingsreferaat wat by die nasionale kongres gelewer is met die bekendstelling van die Suid-

Afrikaanse Genootskap vir Gehalte in Gesondheidsorg. The gehalteverbeteringsproses en -beginsels word ontleed, asook 'n uiteensetting van die Suid-Afrikaanse situasie. Die konsepte betreffende gehalte, gehalteverbetering en gehalieversekering word uitgeklaar, die verskillende rolspelers in geformaliseerde gehalieverbetering word verduidelik, asook die moriewe vir en die beginsels van gehalteverbetering in gesondheidsdienste. Die verskillende eksteme en interme meganismes in gehalieverbetering word ontleed, insluitende die beginsel van eienaarskap deur die gemeenskap, asook internasionale skakeling. Voortgesette ontwikkeling en bemagtiging ten opsigte van gehalteverbetering word op alle vlakke van gesondheidsdienslewering aanbeveel.

\section{LNTRODUCTION}

A person's health is one of the most important assets - therefore health care delivery should be of the highest quality. The health care providers - health care managers, professionals and support staff - have a legal and ethical responsibility to deliver the best possible care, or to facilitate the delivery of quality health care. Quality care is everybody's business - the health care consumer (the patient, the family and community) deserves quality care as the human life is at stake, and the funders of health care expect value for money, adding a cost-effective dimension to quality. It is, therefore clear that health care providers are accountable for the delivery of quality health care services.

Accountability requires proven evidence that quality care has been delivered, in some understandable measurable manner. The evaluation of health care is, therefore, a complex integrated process - the effectiveness of individuals as well as the effectiveness of the total health care delivery system need to be monitored and evaluated. If these results are to be made known to the various stakeholders, the evaluation system should be trustworthy, reflecting the reality of the quality of health care being delivered or rendered by that particular health care delivery system. In the specific field of health care, the growing interest in quality is common to most developed countries; what differs is the means by which it is expressed and the mechanisms by which quality is monitored and evaluated.

\section{Myths}

The first image that usually comes to mind when people start thinking about the quality of health care is that of world class curative care - that is, a health care system which is capable of curing any curable disease in the fastest. most convenient and technically most advanced manner. In short: a system has "quality" if it is as advanced as it can be. It is also the image many people have when they state that quality assurance/improvement is a luxury which can only be afforded by that part of the world which has sufficient resources to procure the latest technology. In this context, quality improvement is more often than not seen as a passing phenomenon - here today and gone tomorrow. But, there is another side to quality - it is a health care system which meets the needs of the people it serves, in the best possible way, within a set of constraints. Quality assurance or improvement is a way of ensuring that a system is as good as it can be, considering the local constraints. If one accepts that allocation of funds to a health system does not automatically increase the quality of the services which the system provides, then one agrees that quality assur ance or improvement is essential in any health care delivery system.

\section{Options}

Every health care organisation is confronted with its inherent problems on a daily basis. The management of these problems requires a purposeful group effort, which could be reactive with the application of crisis management routinely, or a formalised quality improvement system could be in operation to minimise these problems and to enable the delivery of quality care.

A world-class health care organisation, as compared with its primary competitors, creates dynamic processes that (a) go beyond merely meeting internal and extemal patient (customer) needs, desires and expectations; (b) provide distinctive, value-added products and services to customers; and (c) build requisite clinical and competitive capabilities. A world-class organisation uses management approaches and strategies to develop superior core competencies that foster accelerated improvements in human assets, organisation, clinical and management technology, clinical skills, communication and material flows. These core competencies are synergistic with the requirements set by the organisation's mission, suppliers, partners and other stakeholders; they provide a competitive position in the organisation's target market. and create a stock of knowledge for future innovation and success (Roth, 1993:1). The question then arises whether world-class health care can be provided - luxury or challenge? 
The purpose of this article is to explore and describe the fundamental principles of quality improvement in health care service delivery and to analyze the South African position in formalised quality improvement. The content of this article is therefore mainly based on a national and intemational literature analysis and experience gained during the development of a South African Accreditation system in health care.

\section{QUALITY AND QUALITY ASSURANCE/TMPROVEMENT: CONCEPT CLARIFI CATION}

Quality refers to the features or characteristics which are associated with excellence, and these characteristics form the criteria for evaluating the quality of a specific service. The characteristics associated with excellence in health care, can be comprehensively viewed from various perspectives - the patient, the manager, professional practitioner and funder of health care, all perceive quality differently. General criteria associated with health care excellence should, therefore, be formulated, whilst taking cognizance of all these viewpoints.

Quality is defined as having several dimensions (Shaw, 1992:11; WHO, 1983) namely appropriateness, equity, accessibility, effectiveness, acceptability and efficiency. Appropriateness is the key issue and refers to the service or interventions which the individual or community really needs - the right decision and care at the right time. Quality implies a fair share for all the members of society, free from any discrimination. Accessibility means that services are not compromised by undue restrictions in time or distance. Effectiveness is achieving the intended benefit for the individual, family or community.

Services are acceptable when they are provided to satisfy the reasonable expectations of the patient, community, provider and funders. Acceptability should also be viewed within the legal, professional-ethical and cultural context of the various stakeholders and also refers to safety with applicable risk management, adequate professional knowledge and competency, as well as technologically advanced services in accordance with the developments and expectations. Efficiency in health care delivery means that resources are not wasted on one service or patient to the detriment of another.

The terms "quality assurance" and "quality improvement" are widely used in literature. "Assurance" implies a guarantee of quality, in accordance with the characteristics associated with excellence. Because it is not always realistic to guarantee a specific level of health care delivered, the term "improvement" has also been introduced. Quality improvement implies that a formal programme to monitor, measure and evaluate the quality of services delivered is in operation, opportunities for improvement are identified, and a mechanism is provided to take remedial steps to maintain improvements and bring about change and transformation.

\section{STAKEHOLDERS IN THE HEALTH CARE QUALITY MOVEMENT}

There are different stakeholders in the quality movement, requiring a participative approach to foster ownership in the formalisation of quality improvement in health care.

\section{The patient}

The patient is the health care consumer and refers to the individual, family and community. Apart from a patient charter that is being developed in South Africa to protect the patient's rights in health care delivery, the establishment of community development committees at all four levels of health care delivery, is envisaged in terms of the National Health Plan. The patient is also represented, to a lessor extent, by the consumer union.

\section{The health care funder or purchaser}

The health care funder and purchaser are significant stakeholders and should be involved in the quality movement. They are the state - the Department of National Health - as well as the private sector, while medical schemes are also important funders and purchasers of health care in South Africa.

\section{The health care service provider}

Health services are provided at community, district, provincial and national levels by the state and the private sector, all being major roleplayers in the South African quality movement.

\section{The health professionals}

The medical practitioner, the nursing practitioner and the pharmacist are the core members of the front-line and referral health teams in South Africa, assisted by the rehabilitative professional therapists in health care.

\section{The health service managers}

The health service managers at all the levels from the ground level in community health centres to the national level - are responsible for enabling the delivery of quality health care services in South Africa.

All these stakeholders should be involved in the health care quality cycle.

\section{MOTIVES IN FORMALISING QUALITY IMPROVEMENT IN HEALTH CARE}

Why is a formalised approach in quality improvement necessary? There are a number of reasons why quality is assuming increasing importance in health care.

\section{Professional accountability}

The first relates to professional accountability. One of the characteristics of professionalism is the pursuit of excellence and the desire to regulate one's own performance. The professional health practitioner is personally professionally-ethically accountable for his/her practice (acts and omissions). Practitioners are, therefore, eager to become formally involved in quality assurance/improvement (World Health Organization, 1983:3). Certainly, in South Africa, until relatively recently, health care professionals rarely had to account for their actions (or omissions) and, other than professional misconduct by professionals convicted of disgraceful conduct, the activities of health professionals were rarely questioned. However, the public has become increasingly informed about what constitutes good, as well as poor health care.

\section{Financial considerations}

Purchasers and consumers of health services are beginning to state explicitly the kind and quality of health care delivery they expect from health professionals and health care organisations. The incidence of court cases and related claims have increased significantly over the past few years. In addition to this increased perception of what constitutes good health care, is the rapid escalation in health care costs which is placing health care out of reach of significant numbers of people in many countries. Since the concept of quality is associated with the efficient utilisation of resources, quality systems in health care are becoming essential components of the health care environment. The funders of health care want proof of the quality of care delivered.

\section{Quest for excellence}

For professional-ethical reasons, health professionals themselves are realising that they need to have a method of defining and showing that they are providing quality services. Quality improvement activities stimulate resourcefulness, and staff should be afforded the opportunity to initiate and implement innovations which address the key components of quality improvement in the organisation.

\section{Marketing of health services}

Although we all intuitively know what quality means, quality is often difficult to define. This is because quality is not an entity, but varies according to the circumstances which it is applied. It is often easier to know when quality is not present because in most circumstances in which health care is delivered, quality service provision is expected and regarded as normal. Consequently, it is possible to set standards for the delivery of quality health care, based on what is expected and feasible given the present level of medical, technical. managerial and economic resources. The proven evidence of quality health care 
delivery could serve as a marketing principle to be utilised in a professional manner by the health care organisation.

\section{Internal desire to positioning}

The last reason for formalised quality is man's internal desire to position him/herself, to compare his performance with that of another. In this regard the health care practitioner and organisations could become competitive.

\section{PRINCIPLES AND PREREQUISITES OF QUALITY ASSURANCE / IMPROVEMENT}

The success of a formalised quality improvement system is reliant on certain principles that have been proven world-wide (Klazinga, 1994).

\section{Informed commitment}

Informed commitment of the concerned stakeholders is important -it is a concerted group effort which cannot be made in isolation. The necessary information should be given to the roleplayers and the implications thereof and a principle of transparency needs to be maintained, because a formalised approach to quality improvement does mean extra effort and input from all concerned.

\section{Capacity building}

Empowerment of the individual, group and community is necessary, not only in terms of the knowledge and skills required for quality improvement, but also in terms of a positive attitude. In addition to capacity building of the people concerned, organisational development is also required in terms of the $\mathrm{QI}$ infrastructure and information systems to support the process.

\section{Support by management}

Suppor by management is crucial, not only in terms of financial, technological and manpower support, but the process also needs to be driven by a committed and motivated management team who believes in the process and benefits of a formalised approach. A formalised approach in quality improvement also requires the establishment of an information system.

\section{Quality improvement culture}

Quality improvement should not be labelled as a regulatory and bureaucratic system and practices. This requires the development of positive attitudes towards quality improvement activities and the creation of an internal desire to adhere to the standards concerned. A participatory approach in the development, implementation and evaluation of the applicable quality improvement system should therefore be followed.

\section{QUALITY CIRCLE AND ELEMENTS}

Quality assurance or improvement is a formal process of setting standards, monitoring and evaluation of performance against these standards and remedial actions to maintain the standards, improve existing performances and output, as well as facilitating change by means of capacity building. It is a cyclic process standards need to be reviewed continually. The process of quality improvement is analogous to the steps of the systems approach. The quality improvement process consists of certain inputs - i.e. manpower and resources - the process of utilisation of the inputs in rendering care, and the output or results achieved, which is then referred back as part of the input for another cycle of the quality improvement process.

The cycle of quality improvement requires the ability to monitor and measure (such as by observation, document analysis and interviewing) a defined standard (such as a required norm, an agreed target or other expectation) and the ability to respond and change by implementing remedial actions.

\section{a) Standards}

Standards should be developed that clearly and objectively define the way in which clinical services and their supporting systems are rendered and managed. A standard is a written description of the desired level of performance, containing the characteristics associated with excellence, for measuring and evaluating actual performance or service delivery. A standard is an approved statement of something against which measurement can be made and serves as a basis of comparison.

Successful standard formulation require the following (Heideman, 1993:4):

- the belief that standards are desirable and useful;

- the will and knowledge to develop standards;

- the resources for developing the standards and subsequently implementing and maintaining them;

- the ability to promote the standards once they are established and to educate potential users in how to meet them;

- the recognition that standards must be "tailor-made" if they are to serve the specific organisation for which they are intended;

- that someone (group, agency) takes responsibility for the development of standards.

\section{Criteria and indicators}

Once standards have been set, it is necessary to determine how judgements are to be made as to whether or not they have been met. Judgements are made on predetermined criteria. Criteria comprise concrete proof that a standard has been met. This requires the development of indicators which refer to measurable norms or outcome statements. Thus, standard formulation not only involves setting the standards themselves, but also establish ing the criteria which will apply to ascertain whether or not a standard has been met.

\section{Types of standards}

There are three types of standards - structure, process and outcome standards. Structure standards refer to the support system required for health services to be delivered. Structure standards apply to the things we use (human, financial and physical resources). Process standards describe how specific actions should be performed and thus apply to what we do - activities that constinute care, service or management. Outcome standards relate to the objectives that were achieved and address the results, both clinical and non-clinical, of what we do with the things we have (Heideman, 1993:7). Before any form of health care delivery can be evaluated, the necessary standards, therefore, need to be formulated.

\section{Formulation of standards}

Developing standards requires a structured approach which incorporates the following:

- Establishing what is currently regarded as good practice in similar circumstances. This requires a survey of local facilities and is called and "empirical" approach, i.e what is happening in reality, or the inductive method.

- Determining what specialists in the various fields regard as good practice. This is called the normative approach, i.e. what ought to happen. based on deductive reasoning or external control.

- Testing and adapting the normative and empirical approaches (inductive and deductive methods) in the practical situation to ensure that the standards are realistic, under standable, manageable, believable and achievable, thus confirming ownership for the standards.

\section{Phases in standard formulation}

Standard formulation can be divided into three phases: the development phase, the quantifying phase and testing phase. The development phase requires input from experts and grassroots level practitioners and workers. For national/generic standard formulation, committees need to be established with a convenor who has accepted responsibility in this regard and who is committed to the process of quality improvement. Both the empirical and normative approaches are utilised (inductive 
and deductive research methodology) to ensure ownership and trustworthiness of the standards. Draft standards are developed, debated and refined (collective judgement). The quantifying phase implies formal validation or verification of the draft standards. A four-point ordinal rating scale is recommended to quantify the content validity of the standards by means of individual rating (absolute) by experts, or by means of consensus rating by a representative peer group(s). A rating of one means that the standard is irrelevant or not appropriate at all, a rating of two implies lack of clarity and the appropriateness of the standard is questionable. A rating of three implies that the standard is appropriate but not clear and requires reformulation. A rating of four is given to the standard that is complete, clear, well-formulated and highly appropriate or realistic. The standard is consequently accepted, rejected, or reformulation is recommended.

\section{Ownership for the standards, criteria and indicators}

The principle of collective judgement is important -representation by providers, professionals and funders. The development of standards, criteria and/or indicators, is therefore, always done through a consultative process in which consensus among those who will use the standards/indicators is sought, particularly regarding the appropriate level of the standards and how compliance with the standards/indicators will be judged.

\section{Testing of standards}

The final phase implies testing of the standards in practice for a period of time, after which final acceptance/approval of standards takes place, or reformulation is recommended. Within health care, standards are constantly changing to reflect the changing nature of health care itself as reflected in technology, professional practice, economic conditions, consumer expectation, treatment modalities and life expectancies. Thus, standards must be continually revised. Standards are subjected to periodic and on-going review to ensure their continued appropriateness.

\section{Levels of standard formulation}

There are two main approaches in standard formulation: national or generic standards, and specific standards within an organisation. National standards are formulated for general use by all the organisations (eg. hospital standards) and therefore require national input in the formulation and approval thereof. A structured process should be followed (both inductive and deductive research methodology) to ensure ownership and trustworthiness of the standards. These standards, are therefore, transferable (eg. to all hospitals or to all primary health care services in a country). National or generic standards are used for accreditation purposes and are usually published as organisational standards.
National clinical guidelines can be used for indirective professional control and self-evaluation by the professional practitioner.

The specific approach in standard formulation is aimed at formulating standards applicable to specific clinical or non-clinical actions/interventions in a particular health service, department, or even at a health unit-based level, taking into consideration the specific circumstances of the health care service itself.

Standards can also be divided into minimum or optimal standards. Minimum standards are generally thought to represent a level of acceptability below which, in the eyes of those judging, lies the unacceptable. Optimal or desirable standards represent a degree of excellence which may only be achieved by those dedicated and determined to do so (Heideman, 1993:6).

\section{b) Monitoring, measurement and evaluation}

Evaluation refers to the formal way in which information is gathered, interpreted and evaluated in relation to the set standards and criteria. Evaluation requires monitoring and measurement - and measurement requires instruments, with a monitoring system to support and quantify the degree to which health services meet the standards. The monitoring, measurement and evaluation process requires the following:

- a monitoring policy framework and ethical code of conduct to ensure consistency;

- a monitoring instrument which is valid and reliable;

- people to collect the data: monitors, surveyors, etc., complying with the principles of trustworthiness to ensure a representative and true reflection of the reality in terms of the performance which is being monitored;

- a support system in the form of technology and information system, as well as the manpower to enable the transmission of the collected data in the most logical and workable manner, as well as the analysis of the data in the most objective manner to prevent any distortion of the data, complying with all the principles of trustworthiness;

- a system which enables adequate reporting and feedback of the results to the practitioners concerned.

Different monitoring strategies can be utilised, for example self-evaluation, direct observation by the evaluator, the auditing of records and/or document analysis, peer group evaluation, risk/incident monitoring and evaluation, determination of patient satisfaction, interviewing, etc.
Data gathering is a crucial step in the evaluation of the quality of health care rendered. Sufficient data should be gathered to obtain a true reflection of the quality of care in that area/service. This requires representative sampling to ensure trustworthy results. Too little data could give a distorted image, but gathering too much data is expensive and time consuming, which leads to a situation of "data-paralysis". Data analysis and interpretation also need to comply with the principles of trustworthiness to avoid any manipulation of the results. Data gathering and analysis could follow a quantitative approach with sophisticated statistical analysis, or a more qualitative and problem-solving approach could be employed.

\section{c) Remedial action and change/transformation}

The third step in the quality assurance/improvement process is the taking of remedial steps to improve or rectify the results obtained in the evaluation of care. Response mechanisms should be in place to respond effectively to deficiencies identified by the measurement and evaluation system. Staff development programmes should be instituted to address the deficiencies, and managerial structures or activities improved, depending on the outcome of the evaluations. A significant step forward in understanding what is required to provide quality services in health care is the recognition that quality is dependent, not only on the knowledge and skills of clinical practitioners, but also on the way in which the services associated with the provision of clinical services, such as administration, records, etc., are organised and interbinked.

It is not possible to provide high quality health care without coordinating associated clinical and support departments such as radiology, pharmacy and transport. Any department or section within the health care system which does not link, in a coordinated way, with other departments in providing care to individual patients, families and communities, will cause patients to experience poor quality care in some form or another.

\section{QUALITY CONTROL MECHANISMS}

There are basically three broad categories of mechanisms aimed at improving the quality of health care: external programmes, internal quality improvement programmes and indirect professional quality control. Community ownership could also be utilised in a more formalised manner.

\section{a) External mechanisms in formalising quality in health care}

The external programme includes review by legitimate neutral or "outside" bodies such as statutory inspectorates, eg. fires, safety, radiation, educational bodies, like the accreditation of educational institutions, or 
voluntary accreditation bodies and programmes for health care services.

Using accreditation as a means of establishing quality in health care delivery systems

Accreditation is a process whereby national standards are set and compliance with them is evaluated. Generic national standards, focusing on health service organisational capacity building, are formulated by the professions and services at large, and implemented by the specific institu tions or services.

Common areas, within each of these sections in which national organisational (structure) standards are developed, include the following:

- mission and scope of the service;

- management and direction;

- staff: structure and development;

- operational policies/procedures;

- facilities and equipment;

- quality management.

The mission statement is the baseline against which all other standards within the health service and its departments are assessed. The mission statement provides the parameters against which the standards relating to the management system, staff, equipment and operational activities, including the systems by which departments are able to monitor the quality of their own work, can be assessed. Hence the assessment takes into account the capacity of the health service to meet the standards within the framework of the aims and objectives of the health service under review. Standards aimed at improving the quality of health services should seek to ensure that clinical, management and supporting systems are organised and interlinked in a coordinated way that optimises patient care services and the efficient use of resources.

Peer group evaluation is done by a team of external surveyors, based on the guidelines provided in terms of the accreditation programme - a formal accreditation system is followed and involvement in the external accreditation programme is voluntary. The surveyors not only provide an objective. external opinion regarding compliance with standards, but because of their experience, they are also in a position to compare a specific health care facility with the larger group of health care organisations who use a set of standards, thereby providing the facility with information about how it measures up within its peer group. The surveyors may also provide advice to the health care organisation when poor compliance has been achieved, which adds an educational and capacity building dimension to the accreditation process.
Accreditation implies that health services substantially comply with the national organisational standards. This is the basis of accreditation programmes which have been run successfully in many countries over a number of years, and aim to improve the quality of services provided through the process of applying organisational standards in the health services.

An important first phase of such programmes, which lasts six to nine months, is a preparatory phase during which the health services adopt the standards. A self-assessment exercise is carried out, in which the health care facility/organisation judges its own compliance with the standards prior to the arrival of the surveyors.

Before working to implement the standards, the participating services therefore carry out a preliminary internal assessment based on questionnaires developed by the programme. This invariably leads to internal action plans and begins the process of organisational change. A revised response to the questionnaire is then completed towards the end of the preparatory phase. These questionnaires are assessed by trained programme administrators and passed on to extemal surveyors.

The survey phase follows. During a survey, participating services are systematically reviewed by a team of surveyors, complying with the ethical standards of training. professional secrecy and trustworthiness during the survey. Based on their findings, the surveyors generate a report which they initially discuss with the health service management immediately on completion of the survey. A more formal report is then prepared and submitted to an Accreditation Board, assisted by a technical committee.

The Accreditation Board is composed of those organisations and individuals. including purchasers, providers, professionals and the public, who play a significant role in the provision, running and utilisation of health services. Its functions include the following:

- approving and adopting explicit organisational standards;

- receiving and considering reports of surveyors;

- awarding, withholding or discontinuing accroditation of a facility based on clearly defined pass/fail criteria.

Accreditation is generally awarded for a maximum of three years, at which stage the cycle is repeated. Health organisation accreditation programmes are usually nationally based. The responsibility for most accreditation programmes currently in existence generally rests with autonomous organisations, involving multiple roleplayers.

\section{Progress in South Africa}

In South Africa it is assumed that quality in health care can be based largely on the quality of professional training and education. There are few formal mechanisms to define and monitor performance standards for individual hospitals or health care institutions. Although private hospitals are inspected by government inspectors, regulated in terms of the Health Act, the process of inspection varies from region to region. There are no formal inspections of public hospitals or clinics. This deficiency has many implications, including ethical, legal and financial.

\section{Professional-ethical regulation}

The standard of health care practice in South Africa has been regulated by the regulatory bodies, such as the Medical \& Dental Council, Pharmaceutical and Nursing Councils (regulatory bodfes of the former National States included). These organisations act in the interests of the public by ensuring a high standard of training and education, as well as by regulating the practice of health care professionals by means of professional regulations and peer group disciplinary action in the case of professional misconduct. There is no system of credentialling or re-licensing of professionals in South Africa - moves are, however, afoot to develop a system of re-registration of medical practitioners and professional midwives.

\section{Hospital accreditation project}

In order to address the need for a reliable accreditation system in South Africa, the Department of National Health and Population commissioned the Health Management and Administration Unit (University of Stellenbosch Facilitating Unit) of the Department of Community Health. Faculty of Medicine, University of Stellenbosch, to facilitate the development of such a system in collaboration with major stakeholders in the field of health care. The need for such a system arose from a situation where, due to the variation of hospital inspections both intra- and inter-regionally, it has become impossible to objectively evaluate the quality of care rendered by South African health services. This deficiency has many implications, including ethical, legal and financial implications.

Consequently the Pilot Accreditation Project for Health Services was launched in 1993. Dr Charles Shaw, an internationally rocognised authority on quality assurance, President Elect (1993-1994) of the "International Association on Quality in Health Care (ISQA) and Director of the Hospital Accreditation Programme in Bristol United Kingdom, has been assisting with the development of the project (Whittaker \& de Villiers, 1994b).

The aims of the Pilot Accreditation Project for Health Services are to (Whittaker \& de Villiers, 1994b): 
- promote the quality of service rendering by hospitals and primary health care services through developing a comprehensive framework of standards for these services which can be applied nationally;

- develop instruments to assess a hospital's or primary health care service's progress in meeting those standards;

- develop the principles and practice of health service accreditation in hospitals and primary health care services in South Africa.

In striving towards these aims, draft standards and the process were contextualised and refined in pilot hospitals during 1994. During this phase it is of utmost importance that the pilot hospitals actively participate and take ownership of the process and the standards.

Central to the process of hospital accreditation is the Accreditation Facilitating Committee (AFC), which is a select group from within the hospital who, as a team, will activate, initiate, steer and manage the accreditation process. Accreditation Facilitating Committees and survey administrators have been set up in the pilot hospitals. Through their participation in the pilot programmes, these hospitals have shown their commitment to good quality services and are assisting South Africa with the development of standards and a sensible, feasible accreditation system.

Standard development groups were established and draft standards for hospitals were developed, following the generalised (deductive) approach, based on existing international standards, as well as the consensus method (inductive approach) within the specific South African context (Whittaker \& de Villiers, 1994a).

Normative standards have been developed by task groups, comprised of specialists in each discipline/section from different parts of the country. These standards have been provisionally accepted for the pilot project. Six pilot hospitals were chosen from the private and public sector and agreed to test these standards in the practical situation. Thirty-five surveyors, comprising of senior medical clinicians, nurses and managers from the public and private sector, have been trained to act as project surveyors. The six pilot hospitals implemented the standards and have been surveyed towards the end of 1994 and the beginning of 1995. An Interim Accreditation Board was established with members representing the purchasers, providers, professionals and the public. A project on quality improvement for primary health care services has also been initiated by this unit and the standards are presently being formulated.

The Council for Health Service Accreditation of Southern Africa (COHSASA) was established in 1995 and functions as an independent and non-profit making organisation. COHSASA is situated in
Pinelands (Western Cape) and a total of 13 hospitals have been formally surveyed and accredited - the South African Accreditation project has now been successfully established.

b) Clinical guidelines, protocols and indicators as a means of establishing quality in health care (clinical auditing)

Clinical guidelines, protocols and indicators serve as a basis for clinical health care delivery and interaction by the professionals, and refers to the systematic and critical analysis of the quality of clinical health care rendered, including the procedures used for the diagnosis and treatment, the use of resources and the resulting quality of life for the patient (Shaw, 1994). These guidelines, protocols and indicators could be developed both nationally and on a service-based manner. The clinical indicators serve as a basis for comparison in patient compliance with treatment on a national and/or local level.

Clinical auditing therefore implies internal review of clinical and technical quality of practice of health care professionals. This may be professionally led by the specific professional group separately, such as nursing, medical, physiotherapy, etc., or jointly with other professions.

\section{Progress in South Africa}

Clinical guidelines for medical practice are facilitated on a national basis by the Medical Association of South Africa. Many roleplayers are involved in this process and there has been growing acceptance of the concept over the past two years, especially in terms of the benefit this has for managed health care in South Africa. Universal precautions are soon being published as national guidelines and several projects have gained momentum, facilitated by MASA over the past three years.

Many medical practitioners are monitoring their clinical compliance rates on a local and practice-based level, but the development of national indicators for medical intervention is still in its neophyte phase.

As far as nursing practice is concerned, several research studies for Masters degrees have focused on the development of clinical standards for nursing practice, most of which have been published, but no formalised monitoring and evaluation on a national basis are being done. A book on clinical standards, developed by the Johannesburg Hospital's Progressive Nursing Group, has been published. South Africa at large is still in its early developmental stages in this regard.

\section{c) Internal mechanisms in formalising quality in health care}

The internal mechanisms in formalising quality in health care focus mainly on the development of an internal quality improvement programme and total quality management.

Developing a health service-based
quality improvement programme

Any health care institution should have an internal quality improvement programme which focuses on those dimensions which have an impact on quality in that specific institution or service. The setting of standards, monitoring and evaluation of performance and implementing remedial actions resulting in organisational transformation, are initiated and implemented by the staff of the health care institution/service itself in a formalised and structured manner, complying with all the principles of trustworthiness. Although each department in the health service should have a structured quality improvement programme, there should also be evidence of a coordinated quality improvement programme in the health service, with the necessary infrastructure and support systems.

In South Africa the progress in this regard is slowly gaining momentum, especially in those hospitals who participated in the pilot accreditation project. Most of these hospitals did not comply substantially with the standard on departmental quality improvement programmes -this could be due to a lack of knowledge and skills in this regard, as well as time constraints.

\section{Total quality management}

Total quality management implies that quality is incorporated in the management process quality is seen as everybody's business and it is a client-focused process. Management is a process of planning, organising, directing/ leading and control. It is not only lip service to the continuous improvement of health care services, but to have evidence of the implementation of traditional quality processes to include all clinical, managerial/administrative and support personnel in the improvement of the quality health of health services (Koch \& Fairly, 1993:1-5).

Planning implies that commitment to quality health care services is justified in the organisation's mission statement and aims or objectives (including the strategic plan). There is written and practical evidence of a quality improvement programme, with related actions, in the health care organisation. Organising implies that the health care organisation makes provision for a formal quality improvement infrastructure and working mechanism. Quality improvement is seen as one of the elements of service delivery in the health care organisation and provision is made for a post(s) and assigned quality improvement responsibilities to these staff members. There is an appropriate quality committee system in force to facilitate the implementation of quality improvement activities in every service unit of the organisation (clinical, management, support 
services, etc.). The quality improvement activities are organised in the most suitable manner and makes provision for at least risk management, an infection control programme, clinical quality improvement activities, the monitoring, measurement and evaluation of quality health care within the organisation. Just as there is a financial division in the health care organisation, a quality improvement division also exists with a formal infrastructure in place.

Directing or leading relates to the educational, supporting and motivational responsibilities and duties to facilitate the implementation of a quality programme in the health service.

Control implies that a formalised and reliable control system exists for the monitoring and evaluation of quality health care (not just crisis management in this regard), and that appropriate remedial or transformational actions are taken to initiate and implement change.

Total quality management demands an organisational culture that empowers quality improvement of health care services in all settings. Quality is thus seen as an element of the service delivery, but integrated within the management process of the health care organisation.

\section{d) Community ownership}

Community ownership is also a control mechanism whereby pressure can be put onto health services and professional practitioners in the pursuit of excellence. The national media can be used, for example, regular television and newspaper programmes, but will obviously focus more on the complaints of the community. The establishment of community development committees on all the levels of health care delivery in South Africa should contribute towards community participation in the maintenance of health care standards -initially in a more informal manner, but also in a formalised manner when the committees are functioning. The utilisation of an ombudsman in all health professions to facilitate interaction between the different role-players.

\section{INTERNATIONAL COLLABORATION}

The quality movement in health care delivery was initiated by the United States of America, who formalised quality assurance or improvement, developing it into a sophisticated discipline over the past few decades. Many countries followed, of which European countries are focusing on a problem-solving or more qualitative approach to improve the quality of health care delivered. An International Society for Quality Assurance in Health Care (ISQuA) was established in 1985, the main objective being to exchange knowledge and skills related to this complex process. Several South Africans have attended the ISQuA international conferences over the past five years and three South Africans have delivered papers at these conferences. Dr Stuart Whittaker represents Africa on ISQuA's Council. Firm links have been established with Zambia's National Health Department in terms of quality improvement within the African context.

\section{CONCLUSION AND RECOMMENDATIONS}

A formalised quality improvement approach consists of the full quality cycle: the formulation of standards, evaluation of performance against these standards, and purposeful response by means of remedial action. South Africa is in the early phases of formalised quality improvement, both in terms of the external and internal systems. The following recommendations are made:

- The principles of quality improvement should be included in the curriculum of all health professionals.

- The South African Accreditation project (COHSASA) should continue with the implementation and evaluation of the accreditation project, including the development of a primary health care accreditation system.

- The South African Society of Quality in Health (SASQuaH) has a national responsibility to facilitate quality in health care by means of capacity building and support.

- The formation of an Africa-regional Society for Quality in Health Care.

- Continuous education and capacity building in terms of internal quality improvement programmes in all health services.

- The professional organisations should develop professional-practice guidelines for all professions.

\section{CONCLUDING REMARKS}

Quality assurance/improvement in health care is a rapidly growing discipline and embraces the evaluation of the quality of service rendered by the health care professionals. health care institutions or services, such as hospitals, homes for the aged, primary health care services, etc. This requires commitment of all concerned - the health professionals, the management and support staff.

Health care delivery is influenced by many factors today. Future trends worldwide mandate that high quality, cost-efficient care will be the key to the survival of any health care provider. Critics of quality programmes say they may be too restrictive, too expensive and too bureaucratic -this may be true if they are not appropriate. A quality assurancel improvement programme should focus on those structures, actions or interventions and results (outcomes) which have an impact on quality health care, with sufficient collective support and ownership from those who have to implement the programme. Quality improvement in health care is the business of everyone concerned and requires commitment and dedication of all the roleplayers. Questioning the quality of care has not been part of the ethos of health care in this country, but a deliberate effort is being made to formalise quality assurancel improvement in South Africa. Although this is a complex process, it is very rewarding.

\section{REFERENCES}

AFRICAN NATIONAL CONGRESS (1994): National Health Plan. Johannesburg: ANC

BURNHAM, G; MORLOCK, L; MORROW, R \& REINKE, W (1992): Quality assurance management methods for developing countries. Baltimore: Division of Health Systems, Department of International Health.

CHANDLER, GE (1992): The source and process of empowerment. Nursing Administration Quarterty. 16(3), Spring 1992:65-71.

CROSBY, PB (1984): Quality without tears. New York: McGraw Hill

GAUCHER, E \& KRA TOCHWILL, EW (1993): The leader's role in implementing total quality management. Quality Management in Health Care, 1(3) Spring 1993:10-18

HANSAGI, H; CALLTORP, J \& ANDRèASSON, S (1993): Quality comparisons between privately and publicly managed health care centres in a suburban area of Stockholm. Sweden. Quality Assurance in Health Care, 5(1), March: 1993:33-40.

HEIDEMAN, EG (1993): The contemporary use of standards in health care. Geneva: World Health Organization. Division of strengthening of Health Services District Health Systems.

KLAZINGA, N (1994): Concerted action programme on quality assurance in hospitals 1990-1993 (COMAC/HSRQA) Global results on the evaluation. Quality Assurance in Health Care, 6(3). September 1994:219-230.

KOCH, MW \& FAIRLY, TM (1993): Integrated quality management. St Louis: CV Mosby

MULLER, ME (1993): Quality improvernent in a health care service. In: Booyens, SW (Ed) 1993: Dimensions of Nursing Management. Kenwyn: Juta (575-610)

MULLER, ME (1993): The implementation of a quality improvement programme in a nursing service. In: Booyens, SW (Ed) 1993 Dimensions of Nursing Management. St Louis: CV Mosby (609-625)

ROTH, AV (1993): World class health care Quality management in Health Care, 1(3), Spring 1993: 1-9

SHA W, CD (1992): Introducing quality assurance: fourth edition. London: King Edward's Hospital Fund for London.

SHA W, CD (1993): Quality assurance in the United Kingdom. Quality Assurance in Health Care. $5(2): 107 \cdot 118$

SHAW, CD 1994: Quality assurance in the United Kingdom. Quality Assurance in Health Care. 6(3): $107-118$. 
VAN DEN BERG (1993): Quality assurance in district health care, focused on hospitals and health centres. Utrecht: National Organisation for Quality Assurance in hospitals.

WHITTAKER, S \& DE VILLIERS, M (1994a): Standard assessment manual for the Pilot Accreditation Project for Health Services in South Africa. Tygerberg: Health Managemen and Administration Unit, Department of Community Health, Faculty of Medicine, University of Stellenbosch
WHITTAKER, $S$ \& DE VILLIERS, ME (1994b): Accreditation Progress Report. Tygerberg: Health Management and Administration Unit, Department of Community Health, Faculty of Medicine, University of Stellenbosch.

Marie Muller (D.Cur.)

Professor of Nursing,

Rand Afrikaans University

WORLD HEALTH ORGANIZATION (1983):

The principles of quality assurance. EURO

Reports and studies, number 94. Copenhagen:

WHO Regional Office for Europe. 